Bài báo khoa học

\title{
Nghiên cứu xây dựng phương án dự báo lũ Tiểu mãn dựa vào hình thế thời tiết gây mưa lũ khu vực Trung Trung Bộ
}

\author{
Phạm Văn Chiến ${ }^{1}$ Đỗ Thị Phương Linh ${ }^{1 *}$, Nguyễn Thế Long ${ }^{1}$, Nguyễn Minh Tuấn ${ }^{1}$, \\ Nguyễn Văn Khánh ${ }^{1}$ \\ ${ }^{1}$ Đài Khí tượng Thủy văn khu vực Trung Trung Bộ; pvchien@ gmail.com; \\ phuonglinhdo5@gmail.com; thelongol@gmail.com; tuanm18db@gmail.com; \\ nvkhanhkttv@gmail.com; \\ * Tác giả liên hệ: phuonglinhdo5@gmail.com; Tel: +84-978760850 \\ Ban Biên tập nhận bài: 06/11/2020; Ngày phản biện xong: 23/12/2020; Ngày đăng bài: \\ $25 / 1 / 2021$
}

Tóm tắt: Bài báo này là kết quả nghiên cứu xây dựng phương án dự báo lũ Tiểu mãn dựa vào phân loại các hình thế thời tiết gây lũ và phân tích quan hệ mưa lũ, bộ số liệu đưa vào xây dựng phương án từ năm 1978 đến 2019 cho kết quá khá tốt. Kết quả xây dựng phương án sẽ hô̂ trợ cho các dự báo viên trong quá trình tác nghiệp dự báo khả năng xuất hiện lũ Tiểu mãn khu vực Trung Trung Bộ và đáp ứng yêu cầu ngày càng cao của xã hội. Đây là một phương án hiệu quả phục vụ tốt cho công tác dự báo nghiệp vụ trong tương lai.

Từ khóa: Lũ Tiểu mãn; Hình thế thời tiết; Công nghệ dự báo.

\section{Mở đầu}

Nước ta nằm trong vùng khí hậu nhiệt đới gió mùa với các loại thiên tai rất đa dạng. Trong khoảng hơn 20 năm trở lại đây, những hiện tượng thời tiết cực đoan như hạn hán, ngập lụt, sạt lở đất, báo lũ diễn ra ngày càng phức tạp đã làm trên 13.000 người thiệt mạng, bị thương và thiệt hại rất lớn về tài sản và cơ sở hạ tầng [1]. Trong đó lũ lụt là một trong những hiện tượng thời tiết cực đoan gây thiệt hại lớn về người và tài sản, như trận lũ năm 1999 trên các sông từ Quảng Trị đến Quảng Ngãy gây thiệt hại nặng nề, nhất là các tỉnh Thừa Thiên Huế, Quảng Nam, Quảng Trị và thành phố Đà Nẵng, riêng tại tỉnh Thừa Thiên Huế, đã có 372 người chết và thiệt hại hơn 1.780 tỷ đồng. Trận lũ tháng 10 năm 2007 là trận lũ lịch sử trong vòng 45 năm qua ở khu vực Bắc Trung Bộ đã gây vỡ đê trên Sông Bưởi ở Thanh Hóa, lũ quét ở Nậm Giải huyện Quế Phong, Nghệ An..., làm 88 người chết, 8 người mất tích, thiệt hại khoảng 3.215 tỷ đồng [2].

Do các tác hại to lớn do lũ lụt gây ra nên các nghiên cứu trong lĩnh vực này đã được Nhà nước ta quan tâm và phát triển mạnh. Các nghiên cứu tập trung vào phân tích đánh giá đặc điểm, diễn biến lũ, ngập lụt; dự báo lũ, xây dựng bản đồ nguy cơ ngập lụt; nghiên cứu xây dựng các công cụ, hệ thống hỗ trợ khả năng nhận định diễn biến lũ lụt trong cộng đồng, các hệ thống cảnh báo sớm về nguy cơ xảy ra lũ, lũ quét; nghiên cứu xây dựng hành lang thoát lũ.

Lưu vực Sông Gianh, sông Kiến Giang, sông Thạch Hãn, sông Trà Khúc và sông Vệ, nằm trong tọa độ địa lý từ $14^{0} 47^{\prime} 9^{\prime}$ ' đến $17^{0} 43^{\prime}$ 'vĩ độ Bắc và $105^{0} 50^{\prime}$ đến $108^{0} 50$ '36" kinh độ Đông, vào thời kỳ tiết Tiểu mãn thường hay xảy ra các đợt mưa lũ gây thiệt hại nghiêm trọng về sản xuất nông nghiệp, tài sản, ảnh hưởng trực tiếp đến đời sống người dân [3], do đó xây dựng các phương án dự báo, cảnh báo mưa lũ Tiểu mãn là hết sức cần thiết trong công tác phòng chống, giảm nhẹ thiệt hại do lũ lụt gây ra. 


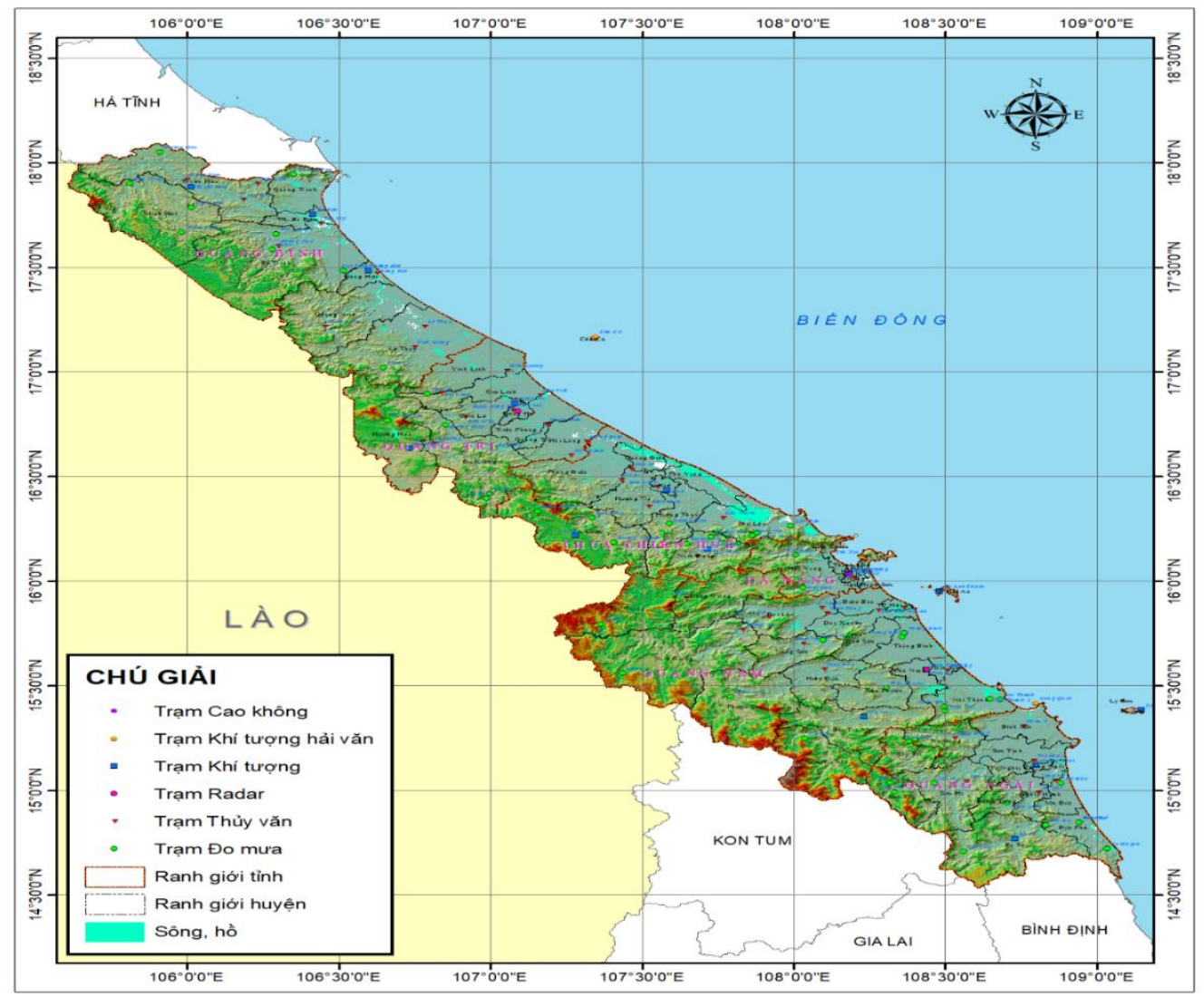

Hình 1. Bản đồ khu vực Trung Trung Bộ.

Các hình thế thời tiết gây mưa lũ Tiểu mãn ở khu vực này rất đa dạng. Qua thống kê, phân tích các đợt mưa lũ Tiểu mãn giai đoạn từ 1978-2019, trên các lưu vực khác nhau có khi cùng một hình thế thời tiết nhưng lũ lại khác nhau, tùy thuộc vào vị trí và địa hình, đặc điểm sông suối. Có đợt mưa lũ gây ra chỉ do một hình thế thời tiết đơn thuần, có những đợt gây lũ do sự kết hợp của các hình thế thời tiết gây nên. Do đó mục tiêu của nghiên cứu là xây dựng được phương án dự báo khả năng xuất hiện lũ Tiểu mãn trên Sông Gianh, sông Kiến Giang, sông Thạch Hãn, sông Trà Khúc, Sông Vệ dựa vào hình thế thời tiết gây lũ.

\section{Cơ sở số liệu và phương pháp nghiên cứu}

\subsection{Cơ sở số liệu}

Để phục vụ cho công tác nghiên cứu, nhóm nghiên cứu tiến hành thu thập số liệu mưa, mực nước của các đợt mưa lũ Tiểu mãn của tất cả các trạm khí tượng thủy văn trên khu vực nghiên cứu từ năm 1978 đến năm 2019 bao gồm:

- Lưu vực Sông Gianh: 02 trạm khí tượng (trạm Tuyên Hóa, Ba Đồn); 2 trạm thủy văn (trạm Đồng Tâm, Mai Hóa); 01 trạm đo mưa (trạm Minh Hóa).

- Lưu vực sông Kiến Giang: 01 trạm khí tượng (trạm Đồng Hới), 02 trạm thủy văn (Kiến Giang và Lệ Thủy), 01 trạm đo mưa (trạm Trường Sơn).

- Lưu vực sông Thạch Hãn: 2 trạm khí tượng (Đông Hà, Khe Sanh), 2 trạm thủy văn (Đông Hà, Thạch Hãn).

- Lưu vực sông Trà Khúc: 1 trạm khí tượng (Quảng Ngãi), 2 trạm thủy văn (Trà Khúc, Sơn Giang), 2 trạm đo mưa (Sơn Hà, Giá Vực).

- Lưu vực sông Vệ: 01 trạm khí tượng (Ba Tơ), 1 trạm thủy văn (An Chỉ), 01 trạm đo mưa (Minh Long).

\subsection{Phưong pháp nghiên cúu}


Dựa vào chuỗi số liệu thống kê các đợt mưa lũ Tiểu mãn từ năm 1978 đến năm 2019 của 20 trạm khí tượng thủy văn trên khu vực nghiên cứu, phân tích bản đồ Synop về hình thế thời tiết xác định được các hình thế gây mưa lũ chính gồm có: Bão hoặc áp thấp nhiệt đới (ATNĐ); bão hoặc ATNĐ kết hợp với một hình thế thời tiết khác; hội tụ gió tây trên cao; hội tụ gió tây trên cao kết hợp với không khí lạnh tăng cường (KKLTC); hội tụ gió tây trên cao kết hợp với rìa nam rãnh áp thấp; rìa nam rãnh áp thấp kết hợp với KKLTC; KKLTC đơn thuần; các loại hình thế thời tiết khác (hoạt động của ãnh thấp có trục tây bắc-đông nam, phía nam rãnh qua Bắc Bộ bị nén và đẩy xuống phía nam,...). Qua số liệu thu thập, thấy rằng các hình thế gây mưa lũ Tiểu mãn với tần suất lớn trên các sông chủ yếu có liên quan đến Hội tụ gió tây, ngoài ra trên lưu vực sông Thạch Hãn còn do bão, lưu vực Sông Vệ do rìa nam rãnh thấp kết hợp với KKLTC.

Bảng 1. Các hình thế chính gây mưa, lũ trên sông Gianh (Trạm Đồng Tâm).

\begin{tabular}{|c|c|c|c|}
\hline Loại & Hình thế thời tiết & Số trận lũ & Tần suất $(\%)$ \\
\hline A & Bão hoặc ATNĐ & 5 & 13 \\
\hline B & Bão hoặc ATNĐ kết hợp một hình thế khác & 3 & 8 \\
\hline $\mathrm{C}$ & Hội tụ gió Tây trên cao & 4 & 10 \\
\hline $\mathrm{D}$ & Hội tụ gió Tây trên cao kết hợp với KKLTC & 5 & 13 \\
\hline $\mathrm{E}$ & Hội tụ gió Tây trên cao kết hợp với rìa nam rãnh thấp & 14 & 35 \\
\hline $\mathrm{F}$ & Rìa nam rãnh thấp kết hợp với KKLTC & 2 & 5 \\
\hline M & Không khí lạnh tăng cường & 2 & 5 \\
\hline G & Các loại hình thế thời tiết khác & 5 & 13 \\
\hline & Tổng & 40 & 100 \\
\hline
\end{tabular}

Bảng 2. Các hình thế chính gây mưa, lũ trên sông Kiến Giang (Trạm Kiến Giang).

\begin{tabular}{|c|c|c|c|}
\hline Loại & Hình thế thời tiết & Số trận lũ & Tần suất $(\%)$ \\
\hline A & Bão hoặc ATNĐ & 6 & 12 \\
\hline B & Bão hoặc ATNĐ kết hợp với một hình thế khác & 3 & 6 \\
\hline $\mathrm{C}$ & Hội tụ gió Tây & 5 & 10 \\
\hline $\mathrm{D}$ & Hội tụ gió Tây trên cao kết hợp với KKLTC & 11 & 22 \\
\hline $\mathrm{E}$ & $\begin{array}{l}\text { Hội tụ gió Tây trên cao kết hợp với rìa nam rãnh áp } \\
\text { thấp }\end{array}$ & 14 & 27 \\
\hline M & Không khí lạnh tăng cường & 3 & 6 \\
\hline G & Các loại hình thế thời tiết khác & 9 & 18 \\
\hline & Tổng & 51 & 100 \\
\hline
\end{tabular}

Bảng 3. Các hình thế chính gây mưa, lũ trên sông Thạch Hãn (Trạm Thạch Hãn).

\begin{tabular}{llcc}
\hline Loại & Hình thế thời tiết & Số trận lũ & Tần suất (\%) \\
\hline A & Bão hoặc ATNĐ & 6 & 50 \\
B & Bão hoặc ATNĐ kết hợp với một hình thế khác & 2 & 17 \\
F & Rìa nam rãnh áp thấp kết hợp với KKLTC & 1 & 8 \\
M & Không khí lạnh tăng cường & 2 & 17 \\
G & Các loại hình thế thời tiết khác & 1 & 8 \\
Tổng hợp & 12 & 100 \\
\hline
\end{tabular}


Bảng 4. Các hình thế chính gây mưa, lũ trên sông Trà Khúc (Trạm Trà Khúc).

\begin{tabular}{|c|c|c|c|}
\hline Loại & Hình thế thời tiết & Số lần lũ & Tần suất (\%) \\
\hline A & Bão hoặc ATNĐ & 8 & 20 \\
\hline B & $\begin{array}{l}\text { Bão hoặc ATNĐ kết hợp với một hình thê thời tiết } \\
\text { khác }\end{array}$ & 3 & 7 \\
\hline $\mathrm{C}$ & Hội tụ gió Tây trên cao & 3 & 7 \\
\hline $\mathrm{D}$ & Hội tụ gió Tây trên cao kết hợp với KKLTC & 5 & 12 \\
\hline $\mathrm{E}$ & $\begin{array}{l}\text { Hội tụ gió Tây trên cao kết hợp rìa nam rãnh áp } \\
\text { thấp }\end{array}$ & 15 & 37 \\
\hline $\mathrm{F}$ & Rìa nam rãnh áp thấp kết hợp với KKLTC & 2 & 5 \\
\hline G & Các hình thế thời tiết khác & 5 & 12 \\
\hline Tổng & & 41 & 100 \\
\hline
\end{tabular}

Bảng 5. Các hình thế chính gây mưa, lũ trên sông Vệ (Trạm An Chỉ).

\begin{tabular}{llll}
\hline Loại & Hình thế thời tiết & Số trận lũ & Tần suất (\%) \\
\hline A & Bão hoặc ATNĐ & 6 & 20 \\
B & Bão hoặc ATNĐ kết hợp với một hình thế khác & 4 & 13 \\
C & Hội tụ gió Tây trên cao & 1 & 3 \\
D & Hội tụ gió Tây trên cao kết hợp với KKLTC & 3 & 10 \\
E & Hội tụ gió Tây trên cao kết hợp với rìa nam rãnh áp & 5 & 17 \\
F & thấp & 7 & 23 \\
G & Rìa nam rãnh thấp kết hợp với KKLTC & 4 & 13 \\
Tổng & Các loại hình thế thời tiết khác & 30 & 100 \\
\hline
\end{tabular}

Sự hình thành lũ là sự kết hợp của nhiều yếu tố trên lưu vực như mưa, tổn thất, độ lớn và hình dạng lưu vực, địa hình, mật độ mạng lưới sông $[5,6,7]$.....Mà mỗi loại hình thế lại gây ra đặc điểm mưa khác nhau trên lưu vực, có khi cùng một loại hình thế tác động lại gây ra mưa khác nhau trên các lưu vực khác nhau, hoặc nhiều khi chịu tác động của hai hình thế thời tiết giống nhau nhưng hình thế này tác động trước hình thế kia tác động sau cũng gây nên lượng mưa khác nhau.

Trên cơ sở xác định được các hình thế gây mưa lũ và số liệu thống kê tổng lượng mưa [8], số ngày mưa của những trận lũ trên các lưu vực xây dựng quan hệ mưa lũ như sau:

$$
\mathrm{H}_{\max }=\mathrm{f}\left(\mathrm{Hc}, \sum \mathrm{Xtblv}, \mathrm{N}\right)
$$

Trong đó $\mathrm{H}_{\max }$ là mực nước đỉnh lũ; $\mathrm{Hc}$ là mực nước chân lũ; $\sum X$ tblv là tổng lượng mưa TBLV; $\mathrm{N}$ là số ngày mưa lớn trên lưu vực.

Mỗi nhân tố trên đều ảnh hưởng lớn đến yếu tố dự báo. Kết quả tính toán cho thấy, tương quan trên đáp ứng được yêu cầu về độ tin cậy, có thể làm công cụ trong dự báo, cảnh báo lũ.

\section{Kết quả và thảo luận}

Dựa trên số liệu thống kê đặc trưng mưa lũ từ năm 1978-2019 cho 5 lưu vực: Sông Gianh, Kiến Giang, Thạch Hãn, Trà Khúc và Sông Vệ, xây dựng phương án dự báo lũ dựa vào các dạng hình thế thời tiết chính. Tuy nhiên trên một số lưu vực số trận lũ gây ra bởi cùng một hình thế không nhiều, khi xây dựng riêng kết quả có độ tin cậy không cao, do đó ta xây dựng một số phương án gộp một vài hình thế thời tiết lại, phương án nào cho kết quả tốt nhất sẽ được lựa chọn. 
Bảng 6. Kết quả đánh giá phương án dự báo tại Đồng Tâm.

\begin{tabular}{|c|c|c|c|c|c|}
\hline Hình thế thời tiết & $\begin{array}{c}\text { Hệ số tương } \\
\text { quan }\end{array}$ & $\begin{array}{c}\text { Mức đảm bảo } \\
\text { P\% }\end{array}$ & $\eta$ & $\sigma / \sigma$ & Xếp loại \\
\hline $\begin{array}{l}\text { Ảnh hưởng của } 1 \text { loại hình } \\
\text { thế thời tiết }\end{array}$ & 0,85 & 77 & 0,85 & 0,27 & Đạt \\
\hline $\begin{array}{l}\text { Sự kết hợp của hai hình } \\
\text { thế thời tiết gây lũ trở lên }\end{array}$ & 0,80 & 96 & 0,80 & 0,36 & Đạt \\
\hline
\end{tabular}

Bảng 7. Kết quả đánh giá phương án dự báo tại Kiến Giang.

\begin{tabular}{|c|c|c|c|c|c|}
\hline \multirow{2}{*}{ Hình thế thời tiết } & \multicolumn{2}{|c|}{ Hệ số tương Mức đảm bảo } & \multirow[b]{2}{*}{$\eta$} & \multirow{2}{*}{$\sigma / \sigma$} & \multirow{2}{*}{ Xếp loại } \\
\hline & quan & $\mathbf{P \%}$ & & & \\
\hline \multicolumn{6}{|l|}{ Bão hoặc ATNĐ, Bão hoặc } \\
\hline $\begin{array}{l}\text { ATNĐ kết hợp } 1 \text { hình thế thời } \\
\text { tiết khác }\end{array}$ & 0,88 & 89 & 0,94 & 0,12 & Tốt \\
\hline Hội tụ gió tây, Hội tụ gió tây & & & & & \\
\hline $\begin{array}{l}\text { kết hợp KKLTC, Hội tụ gió } \\
\text { tây kết hợp rìa nam rãnh áp } \\
\text { thấp }\end{array}$ & 0,76 & 77 & 0,75 & 0,44 & Dùng Tạm \\
\hline $\begin{array}{l}\text { Các hình thế thời tiết khác, } \\
\text { không khí lạnh }\end{array}$ & 0,75 & 80 & 0,75 & 0,44 & Dùng tạm \\
\hline
\end{tabular}

Bảng 8. Kết quả đánh giá phương án dự báo tại Thạch Hãn.

\begin{tabular}{lcccccc}
\hline Hình thế thời tiết & $\begin{array}{c}\text { Hệ số tương } \\
\text { quan }\end{array}$ & $\begin{array}{c}\text { Mức đảm } \\
\text { bảo } \mathbf{P} \%\end{array}$ & $\boldsymbol{\eta}$ & $\boldsymbol{\sigma} \%$ / & Xếp loại \\
\hline Tất cả các hình thế & 0.77 & 62 & 0.78 & 0.39 & Dùng tạm \\
\hline
\end{tabular}

Bảng 9. Kết quả đánh giá phương án dự báo tại Trà Khúc.

\begin{tabular}{|c|c|c|c|c|c|}
\hline \multirow{2}{*}{ Hình thế thời tiết } & \multicolumn{2}{|c|}{ Hệ số tương Mức đảm bảo } & \multirow[b]{2}{*}{$\eta$} & \multirow[b]{2}{*}{$\sigma / \sigma$} & \multirow[b]{2}{*}{ Xếp loại } \\
\hline & quan & $\mathbf{P \%}$ & & & \\
\hline $\begin{array}{l}\text { Ảnh hưởng của } 1 \text { loại hình thế } \\
\text { thời tiết }\end{array}$ & 0,88 & 75 & 0,88 & 0,23 & Đạt \\
\hline $\begin{array}{l}\text { Sự kết hợp của hai hình thế } \\
\text { thời tiết gây lũ trở lên }\end{array}$ & 0,90 & 91 & 0,90 & 0,18 & Tốt \\
\hline
\end{tabular}


Bảng 10. Kết quả đánh giá phương án dự báo tại An Chỉ.

\begin{tabular}{|c|c|c|c|c|c|}
\hline Hình thế thời tiết & $\begin{array}{c}\text { Hệ số tương } \\
\text { quan }\end{array}$ & $\begin{array}{c}\text { Mức đảm } \\
\text { bảo P\% }\end{array}$ & $\eta$ & $\sigma / \sigma$ & Xếp loại \\
\hline \multicolumn{6}{|l|}{ Bão hoặc ATNĐ, Bão hoặc } \\
\hline $\begin{array}{l}\text { ATNĐ kết hợp } 1 \text { hình thế } \\
\text { thời tiết khác }\end{array}$ & 0,86 & 78 & 0,94 & 0,13 & Đạt \\
\hline $\begin{array}{l}\text { Hội tụ gió tây, Hội tụ gió tây } \\
\text { trên cao kết hợp KKL, Hội tụ }\end{array}$ & & & & & \\
\hline $\begin{array}{l}\text { gió tây trên cao kết hợp rìa } \\
\text { nam rãnh thấp, rìa nam rãnh } \\
\text { áp thấp bị nén kết hợp }\end{array}$ & 0,80 & 94 & 0,94 & 0,11 & Tốt \\
\hline $\begin{array}{l}\text { KKLTC, các hình thế thời } \\
\text { tiết khác }\end{array}$ & & & & & \\
\hline
\end{tabular}

Bảng 11. Đánh giá chất lượng dự báo trị số tại Đồng Tâm và Kiến Giang.

\begin{tabular}{|c|c|c|c|c|c|c|c|c|c|}
\hline \multicolumn{4}{|c|}{ Đồng Tâm } & \multicolumn{6}{|c|}{ Kiến Giang } \\
\hline \multicolumn{2}{|c|}{$\begin{array}{c}\text { Ảnh hưởng của } 1 \\
\text { loại hình thế thời } \\
\text { tiết }\end{array}$} & \multicolumn{2}{|c|}{$\begin{array}{l}\text { Sự kết hợp của } \\
\text { hai hình thế thời } \\
\text { tiết gây lũ trở lên }\end{array}$} & \multicolumn{2}{|c|}{$\begin{array}{l}\text { Bão hoặc ATNĐ, } \\
\text { Bão hoặc ATNĐ kết } \\
\text { hợp } 1 \text { hình thế thời } \\
\text { tiết khác }\end{array}$} & \multicolumn{2}{|c|}{$\begin{array}{l}\text { Hội tụ gió tây, Hội tụ } \\
\text { gió tây kết hợp } \\
\text { KKLTC, Hội tụ gió } \\
\text { tây kết hợp rìa nam } \\
\text { rãnh áp thấp }\end{array}$} & \multicolumn{2}{|c|}{$\begin{array}{l}\text { Các hình thế } \\
\text { thời tiết khác, } \\
\text { không khí lạnh }\end{array}$} \\
\hline $\begin{array}{l}\text { Xếp } \\
\text { loại }\end{array}$ & $\mathrm{P} \%$ & Xếp loại & $\mathrm{P} \%$ & Xếp loại & $\mathrm{P} \%$ & Xếp loại & $\mathrm{P} \%$ & Xếp loại & $\mathrm{P} \%$ \\
\hline Tốt & 18 & Tốt & 50 & Tốt & 22 & Tốt & 26 & Tốt & 30 \\
\hline Khá & 27 & Khá & 21 & Khá & 11 & Khá & 22 & Khá & 20 \\
\hline Đạt & 27 & Đạt & 25 & Đạt & 56 & Đạt & 30 & Đạt & 30 \\
\hline Kém & 13 & Kém & 4 & Kém & 11 & Kém & 19 & Kém & 10 \\
\hline $\begin{array}{l}\text { Quá } \\
\text { kém }\end{array}$ & 9 & Quá kém & 0 & Quá kém & 0 & Quá kém & 4 & $\begin{array}{l}\text { Quá } \\
\text { kém }\end{array}$ & 10 \\
\hline
\end{tabular}

Bảng 12. Đánh giá chất lượng dự báo trị số tại Thạch Hãn và Trà Khúc.

\begin{tabular}{|c|c|c|c|c|c|c|c|}
\hline Thạch Hãn & \multicolumn{3}{|c|}{ Trà Khúc } & \multicolumn{4}{|c|}{ AnChỉ } \\
\hline $\begin{array}{c}\text { Tất cả các hình } \\
\text { thế }\end{array}$ & $\begin{array}{c}\text { Ảnh hưởng của } 1 \text { loại } \\
\text { hình thế thời tiết }\end{array}$ & $\begin{array}{r}\text { Sựkếthợpc } \\
\text { hình thế thời ti } \\
\text { trở lên }\end{array}$ & gâylũ & $\begin{array}{l}\text { Bão hoặc } \\
\text { hoặc ATN } \\
\text { hình thếtl }\end{array}$ & $\begin{array}{l}\boxplus \text { Đ, Bão } \\
\text { t̂thọp } 1 \\
\text { êt khác }\end{array}$ & $\begin{array}{l}\text { Hội tụ gió tâ } \\
\text { trên cao kêth } \\
\text { gió tây trên ca } \\
\text { rãnh thấp, rìa } \\
\text { bịnén kếthọ } \\
\text { hình thết }\end{array}$ & $\begin{array}{l}\text { giót tây } \\
\text { Hội tụ } \\
\text { rìanam } \\
\text { náp thấp } \\
\text { rC, các } \\
\text { hác }\end{array}$ \\
\hline $\begin{array}{l}\text { Xếp } \\
\text { loại }\end{array}$ & Xếp loại & Xếp loại & $\mathrm{P} \%$ & Xếp loại & $\mathrm{P} \%$ & Xếp loại & $\mathrm{P} \%$ \\
\hline Tốt & Tốt & Tốt & 45 & Tốt & 22 & Tốt & 33 \\
\hline
\end{tabular}




\begin{tabular}{cccccccccc}
\hline Khá & 8 & Khá & 27 & Khá & 21 & Khá & 33 & Khá & 22 \\
Đạt & 39 & Đạt & 21 & Đạt & 24 & Đạt & 22 & Đạt & 39 \\
$\begin{array}{r}\text { Kém } \\
\text { Quá }\end{array}$ & 38 & Kém & 25 & Kém & 7 & Kém & 0 & Kém & 0 \\
kém & 0 & Quá kém & 0 & Quá kém & 3 & Quá kém & 22 & Quá kém & 6 \\
\hline
\end{tabular}

Kết quả xây dựng phương án dự báo đỉnh lũ Tiểu mãn theo các dạng hình thế thời tiết điển hình trên lưu vực Sông Gianh, Kiến Giang, Thạch Hãn, Trà Khúc, Sông Vệ thấy tương quan giữa các yếu tố khá chặt chẽ (hệ số tương quan xây dựng phương án dao động từ $0,75-$ $0,90)$.

Kết quả đánh giá phương án trên lưu vực Sông Gianh, Thạch Hãn, Trà Khúc cho thấy, tất cả các phương án đều có thể sử dụng trong nghiệp vụ dự báo, nhất là trong trường hợp mưa tập trung trong thời gian ngắn từ $1-2$ ngày đối vơi lưu vực Sông Gianh và Kiến Giang, 2-3 ngày đối với lưu vực sông Trà Khúc, Sông Vệ. Tuy nhiên, một số trận lũ có tổng lượng mưa lớn nhưng đỉnh lũ lại không cao. Nguyên nhân là do mưa không liên tục, kéo dài nhiều ngày và cường độ mưa không đều, gây nên lũ kép có 2 hoặc nhiều đỉnh liên tiếp nên thường rất khó dự báo; một nguyên nhân nữa có thể đề cập đến là vị trí đặt trạm đo mưa không đủ đại diện cho mưa trên khu vực đó.

Phương án Hội tụ gió tây, Hội tụ gió tây kết hợp với KKL, Hội tụ gió tây kết hợp rìa nam rãnh thấp và phương án các hình thế thời tiết khác, không khí lạnh cho lưu vực sông Kiến Giang cho chỉ số $\eta$ không cao, nguyên nhân dẫn đến kết quả tính toán như vậy là do điểm đặt trạm đo mưa trên thượng nguồn rất thưa, lượng mưa lưu vực không đủ đại diện cho toàn bộ lưu vực. Phương án án dự báo trên lưu vực sông Thạch Hãn cũng có thể dùng tạm trong nghiệp vụ dự báo, chỉ số $\eta=0,78$ và mức đảm bảo đạt $62 \%$. Nguyên nhân mức đảm bảo chỉ đạt $62 \%$ là do khi tách ra thành nhiểu phương án theo hình thế thời tiết thì số lượng các đợt mưa lũ quá ít, không đủ phản ảnh đúng về mưa lũ trên lưu vực, tuy nhiên khi gộp các hình thế thời tiết lại với nhau, mỗi loại hình thế thời tiết lại có đặc điểm mưa, lũ khác nhau, dẫn đến chất lượng phương án chỉ ở mức dùng tạm.

Qua thống kê số liệu mưa lũ Tiểu mãn trong vòng 41 năm (1978-2019) cho thấy với mỗi loại hình thế thời tiết khi tác động đến lưu vực sông sẽ gây ra lượng mưa khác nhau, ngay trong cùng 1 nhóm hình thế tác động cũng có thể gây ra lượng mưa khác nhau tùy thuộc vào hình thế nào tác động trước, hình thế nào tác động sau. Mỗi hình thế tác động cũng gây ra phân bố lượng mưa khác nhau cho các trạm trên lưu vực theo không gian. Từ kết quả xây dựng phương án dự báo, cảnh báo lũ Tiểu mãn cho 05 lưu vực sông cho thấy, mỗi lưu vực khi kết hợp các hình thế giống nhau lại cho ra kết quả có chất lượng dự báo khác nhau.

\section{Kết luận}

Nghiên cứu đã xây dựng được phương án dự báo lũ Tiểu mãn dựa vào hình thế thời tiết gây mưa lũ Tiểu mãn, nâng cao hiệu quả dự báo lũ Tiểu mãn tại địa phương, góp phần làm giảm nhẹ các thiệt hại do thiên tai gây ra và góp phần phát triển bền vững kinh tế xã hội, đảm bảo an ninh quốc phòng. Tuy nhiên để nâng cao chất lượng của phương án thì trên một số lưu vực sông cần phải bố trí thêm các trạm đo mưa, đặc biệt khu vực phía thượng lưu các sông.

Đóng góp của tác giả: Xây dựng ý tưởng nghiên cứu: D.T.P.L., N.T.L., P.V.C.; Lựa chọn phương pháp nghiên cứu: P.V.C., D.T.P.L.; Xử lý số liệu: N.V.K., N.M.T.; Xây dựng phương án: D.T.P.L., N.T.L., P.V.C., N.M.T., N.V.K.; Viết bản thảo bài báo: D.T.P.L., N.T.L., P.V.C.; Chỉnh sửa bài báo: N.V.K., N.M.T., D.T.P.L.

Lời cảm ơn: Nghiên cứu này được thực hiện trong đề tài cấp cơ sở "Nghiên cứu đánh giá khả năng xuất hiện lũ Tiểu mãn các sông khu vực Trung Trung Bộ”, mã số CS.2020.05.07. 
Bên cạnh đó, tập thể tác giả trân trọng cảm ơn sự giúp đỡ của các anh chị em trong Đài Khí tượng Thủy văn khu vực Trung Trung Bộ, đặc biệt lãnh đạo đơn vị trong quá trình nghiên cứu.

Lời cam đoan: Tập thể tác giả cam đoan bài báo này là công trình nghiên cứu của tập thể tác giả, chưa được công bố ở đâu, không được sao chép từ những nghiên cứu trước đây; không có sự tranh chấp lợi ích trong nhóm tác giả.

\title{
Tài liệu tham khảo
}

1. Cát, V.M. Đánh giá rủi ro thiên tai do lũ lụt lưu vực sông Dinh. Tạp chí Khí tượng Thủy văn 2020, 717, 1-10.

2. Hòa, T.Q. Nghiên cứu xây dựng công nghệ nhận dạng lũ sông Hồng phục vụ điều hành hồ Hòa Bình. Báo cáo tổng kết Đề tài cấp Bộ, 1992.

3. Sơn, N.T. Đặc điểm lũ tiểu mãn sông ngòi Bắc-Trung Bộ và các biện pháp phòng chống. Báo cáo tổng kết Đề tài cấp Bộ, 1993.

4. Sơn, N.H. Đánh giá vai trò của các hình thế thời tiết gây mưa lũ ở lưu vực sông Hương, tỉnh Thừa Thiên Huế-giai đoạn 1976-2013. Tạp chi khoa họ ĐHSP TPHCM 2014, 61, 34-43.

5. Giáo trình Dự báo Thủy văn, nhà xuất bản Đại học Quốc gia Hà Nội, 2003.

6. Giáo trình dự báo thủy văn, Đại học tài nguyên và môi trường Hà Nội, 2003.

7. Giáo trình Thủy văn Công Trình, Đại học Thủy lợi, 2008.

8. Long, V.Đ. Nghiên cứu xây dựng công nghệ cảnh báo, dự báo lũ và cảnh báo ngập lụt cho các sông chính ở Quảng Bình, Quảng Trị. Báo cáo tổng kết Đề tài cấp bộ, 2014.

\section{Xiaoman flood forecasing based on weather system caused flood in mid-central region}

\section{Pham Van Chien ${ }^{1,}$ Do Thi Phuong Linh ${ }^{*}$, Nguyen The Long ${ }^{1}$, Nguyen Minh Tuan ${ }^{1}$, Nguyen Van Khanh ${ }^{1}$}

${ }^{1}$ Mid-central regional Hydro-meteorological center; pvchien@gmail.com; phuonglinhdo5@gmail.com; thelongol@gmail.com; tuanm18db@gmail.com; nvkhanhkttv@gmail.com

\begin{abstract}
This article is the result of research and development of Xiaoman flood forecasting plan based on weather systems causing floods in the Mid-cental Region, the set of data included in the plan development from 1978 to 2019 gave a good result. The result of the plan development will support the forecasters in forecasting the possibility of appearing Xiaoman flood in the Mid-central region and meet the increasing demands of society. This is an effective flood forecating in operational conditions in the future.
\end{abstract}

Keywords: Xiaoman flood; Weather system; Forecasting technology. 